\title{
Prevalence of Chlamydia pneumoniae seropositivity in early pregnancy and its association with preeclampsia among primigravidae in Indian population
}

\author{
Lavi Sindhu1, Bindoo Yadav ${ }^{2 *}$, Aruna Batra ${ }^{2}$
}

\begin{abstract}
${ }^{1}$ Department of Obstetrics and Gynecology, Safdarjung Hospital and Vardhman Mahavir Medical College, New Delhi, India

${ }^{2}$ Department of Obstetrics and Gynecology, SGT Med College and Research Centre, Gurugram, Haryana, India
\end{abstract}

Received: 12 July 2019

Accepted: 30 August 2019

\section{*Correspondence:}

Dr. Bindoo Yadav,

E-mail: abvy90@yahoo.co.in

Copyright: ( ) the author(s), publisher and licensee Medip Academy. This is an open-access article distributed under the terms of the Creative Commons Attribution Non-Commercial License, which permits unrestricted non-commercial use, distribution, and reproduction in any medium, provided the original work is properly cited.

\begin{abstract}
Background: Preeclampsia (PE) is a multifactorial disease that might be caused by a concurrent or preceding inflammatory stimulus. Inflammatory changes similar to those reported in chronic Chlamydia pneumoniae infection are seen in PE. It is suggested that persistent or chronic Chlamydia pneumoniae infection might have a role in the pathogenesis of PE and antichlamydial treatment in early pregnancy may prevent reactivation of infection and hence the development of preeclampsia.

Methods: This randomized interventional study was conducted to determine the prevalence of C.pneumoniae IgG seropositivity in early pregnancy, its association with PE and the effect of treatment with oral azithromycin. A total of 330 primigravidae included in the study were followed up till delivery. C.pneumoniae IgG antibodies measured by ELISA technique at 14-20 weeks of gestation revealed seropositivity in $32.4 \%$. These women were at higher risk of developing severe PE (odds' ratio 3.2) as compared to the $C$. pneumoniae seronegative cases.

Results: Treatment with oral azithromycin resulted in reduction in the occurrence of PE amongst the C.pneumoniae seropositive cases; as well as significant reduction in the incidence of low birth weight babies in the C.pneumonie seropositive group $(\mathrm{p}<0.001, \mathrm{ARR}=0.204)$.

Conclusions: Pregnant women who were C.pneumonia IgG seropositive are at higher risk of developing severe preeclmapsia as compared to the C.pneumoniae seronegative cases. This association needs to be further evaluated.
\end{abstract}

Keywords: Azithromycin, C.pneumonia, IgG sero-positivity, Prevalence, Pre-eclampsia, Primigravida

\section{INTRODUCTION}

Preeclampsia is a major cause of maternal and perinatal mortality and we still have limited ability for its prevention. The incidence of preeclampsia ranges between $2 \%$ to $10 \%$ of pregnancies and is estimated by WHO to be seven times higher in developing countries. ${ }^{1}$ Despite a lot of research into understanding its etiology and pathogenesis, the mechanisms by which preeclampsia occurs is not certain; numerous maternal, paternal, and fetal factors have been implicated, and basic pathology is endothelial dysfunction, involving blood vessels in the body as well as uteroplacental system., ${ }^{2,3}$ There is increasing evidence that inflammation plays a key role in pathogenesis of PE. Mild systemic inflammatory response of normal pregnancy is being exaggerated in PE and there might be a role of concurrent or preceding inflammatory stimulus such as infection in 
pathogenesis of preeclampsia, which is substantiated by systematic review of epidemiologic studies and also the association of urinary tract infection and periodontal disease during pregnancy with an increased risk of PE. ${ }^{4-6}$

C.pneumoniae is an obligatory intracellular gram negative bacterium and is a leading cause of human respiratory tract infections worldwide. It has been proposed that during respiratory tract infection C.pneumoniae reaches vascular tissue via infected leukocytes and it has the capacity to infect and multiply in vascular endothelial and smooth muscle cells. ${ }^{7}$ Recently, C.pneumoniae has been considered potential risk factor for atherosclerosis. ${ }^{8} 9 \mathrm{PE}$ and atherosclerosis share many common pathophysiologic features and risk factors; lipid profile changes, foam cell invasion and fibrinoid deposition similar to atherosclerosis are also seen in placental blood vessels among preeclamptics. ${ }^{10,11}$

The sero-prevalence of C.pneumoniae infection in pregnancy has been reported to be as much as 27.8 to 77\%. ${ }^{12-14}$ Association between C.pneumoniae seroprevalence and preeclampsia has been proven by many studies. ${ }^{13-19}$ El-Shourbagy MA et al, in one study showed a reduced incidence of preeclampsia after giving treatment to C.pneumoniae seropositive women. ${ }^{17}$ However, other studies showed conflicting results. ${ }^{20-22}$ Xie $\mathrm{F}$ et al, recommended need for further studies. ${ }^{23}$ Mosbah et al, studied the effect of Helicobacter pylori, Chlamydiae pneumoniae and trachomatis as probable etiological agents of preeclampsia and recommended further studies. ${ }^{24}$ No such studies have been conducted amongst Indian population. So, the present study was planned to determine the prevalence of C.pneumoniae IgG seropositivity in early pregnancy, its association with preeclampsia and the effect of treatment with oral azithromycin, among primigravidae in north Indian population, in a tertiary care centre.

\section{METHODS}

A randomized interventional study was conducted in the Department of Obstetrics and Gynaecology and Microbiology laboratory (ICMR) at Vardhman Mahavir Medical College and Safdarjung Hospital, New Delhi between October 2011 to March 2013 after taking the clearance from ethical committee. A minimum sample size of 330 was calculated based on estimated seroprevalence of C.pneumoniae in pregnancy as $37 \%$, anticipated prevalence of preeclampsia as $7 \%$, confidence limit as $95 \%$, power of study as $80 \%$ and $5 \%$ dropout.

Women who attended the antenatal clinic were screened. Primigravidae with a viable singleton pregnancy at 14-20 weeks, willing to comply with the protocol, were selected for inclusion in the study. All those women with preexisting diabetes mellitus, chronic hypertension, renal disorders and multiple pregnancy were excluded. Following an informed consent, all the women included in the study had an estimation of IgG antibodies against
C.pneumoniae by enzyme linked immunosorbent assay (ELISA) technique, using a commercial kit manufactured by IBL International (GmbH, Germany). ELISA technique was chosen because of commercial availability, ease of performance, and objective end point.

Based on C.pneumoniae serology results the study population was divided into seropositive and seronegative groups. The seropositive group was further sub-divided randomly into the treatment and non-treatment groups. The treatment group received Azithromycin for C.pneumoniae. Randomization was done by computer generated table.

All the patients had regular detailed antenatal check-up and were followed up monthly till 32 weeks, fortnightly till 36 weeks, and weekly thereafter till delivery. Those who developed preeclampsia received appropriate fetal and maternal monitoring and antihypertensive therapy if required. Preeclampsia was defined as new hypertension (diastolic blood pressure of $90 \mathrm{mmHg}$ or more on at least two occasions at least 4 hours apart) and new proteinuria (protein concentration of $1 \mathrm{~g} / \mathrm{l}$ or more as detected by dipstick test in 2 midstream urine samples collected more than 4 hours apart, or presence of at least $300 \mathrm{mg}$ protein in a 24-hour urine collection) occurring after 20 weeks of pregnancy. Severe PE was defined as the presence of high blood pressure $(160 / 110 \mathrm{~mm} \mathrm{Hg}$ or more), protienuria (more than $5 \mathrm{~g}$ protein in 24 hours urine collection), oliguria (urine output $<400 \mathrm{ml}$ in 24 hours), thrombocytopenia (platelet count $<100,000 / \mathrm{ml}$ ), visual disturbances, epigastric pain, impaired liver function, or occurrence of any complication.

\section{Statistical analysis}

Statistical analysis of data was done using chi square test for qualitative variables and t-test for the continuous variables. Mean values and standard errors were calculated by using analysis of variance (ANNOVA). Level of significance $(\alpha)$ taken as $5 \%$, p value $<0.05$ taken as statistically significant. Odds' ratio was calculated to find the probability of increase in incidence of disease due to presence of seropositivity to C.pneumoniae. Absolute risk reduction (ARR) and number needed to treat (NNT) were calculated to report the effect of intervention on each outcome.

\section{RESULTS}

A total of 400 women were screened (Figure 1), of which 70 were excluded from the study as per the exclusion criteria (Diabetes-3, renal disease-1, twin pregnancy-4, chronic hypertension-5, not compliant with the study protocol-52/ loss to follow up-5). Thus 330 women were followed up till delivery and included in the final analysis. Out of these, 108 women were seropositive (study group) and 222 were seronegative (control group). Hence, the prevalence of seropositivity to C.pneumoniae IgG among the study population was $32.4 \%$ (108/330). 


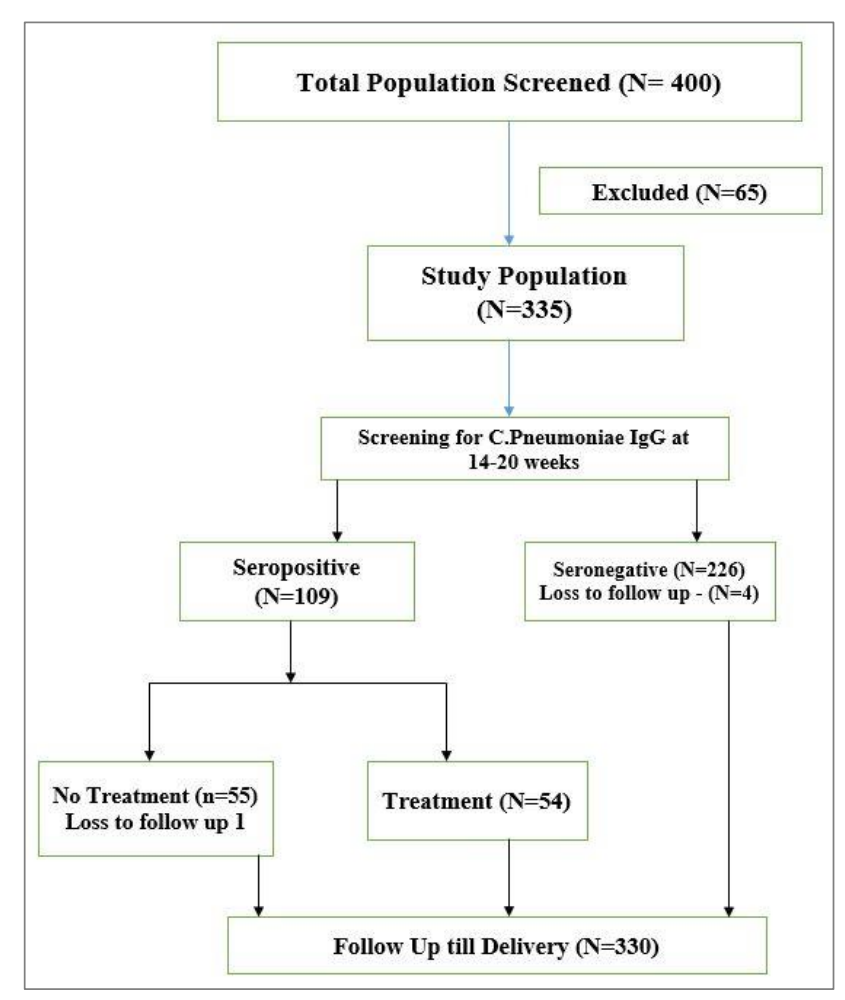

Figure1: Study population flow chart.

Both the groups were comparable with respect to age, socioeconomic status and BMI (Table 1). Majority of the women in both the groups were between 20-25 years of age, mean age being $23.06 \pm 2.55$ years in seropositive and $23 \pm 3.24$ years in the seronegative group. Mean BMI was $20.32 \pm 2.59 \mathrm{~kg} / \mathrm{m}^{2}$ in seropositive group and $20.23 \pm 2.73$ $\mathrm{kg} / \mathrm{m}^{2}$ in the seronegative group.

Preeclampsia was seen in 19 cases amongst the total study population of 330 cases; 16 mild and 3 severe; 2 early-onset and 17 late-onset (Table 2). The incidence of preeclampsia in the C.pneumoniae seropositive-untreated group was $13 \%(7 / 54)$ as compared to $4 \%(9 / 222)$ in the seronegative group $(\mathrm{p}=0.02)$. Thus, the seropositive untreated group was at a higher risk of developing preeclampsia as compared to the seronegative group (odd's ratio 3.52). Incidence of preeclampsia was lower in the seropositive treated group $(5.6 \%)$ than the seropositive untreated group (13\%). However, it was not statistically significant $(\mathrm{p}=0.32)$.

Table 1: Patient characteristics.

\begin{tabular}{|c|c|c|}
\hline & $\begin{array}{l}\text { C.pneumoniae } \\
\text { seropositive } \\
(\mathrm{N}=108)\end{array}$ & $\begin{array}{l}\text { C.pneumoniae } \\
\text { seronegative } \\
(\mathrm{N}=222)\end{array}$ \\
\hline & No. $(\%)$ & No. $(\%)$ \\
\hline \multicolumn{3}{|c|}{ Age group (years) } \\
\hline$<20$ & $06(5.6)$ & $16(7.2)$ \\
\hline $20-25$ & $78(72.2)$ & $166(74.8)$ \\
\hline $26-30$ & $21(19.4)$ & $37(16.7)$ \\
\hline$>30$ & $03(2.8)$ & $03(1.3)$ \\
\hline \multicolumn{3}{|l|}{ BMI } \\
\hline$<18.5$ & $24(22.2)$ & $49(22.1)$ \\
\hline $18.5-24.9$ & $76(70.4)$ & $149(67.1)$ \\
\hline$\geq 25$ & $08(7.4)$ & $24(10.8)$ \\
\hline \multicolumn{3}{|l|}{ Education } \\
\hline Illiterate & $43(39.8)$ & $40(18.0)$ \\
\hline Primary & $30(27.8)$ & $72(32.4)$ \\
\hline Middle & $25(23.1)$ & $73(32.9)$ \\
\hline Graduate & $10(9.3)$ & $37(16.7)$ \\
\hline \multicolumn{3}{|l|}{ Residence } \\
\hline Rural & $44(40.7)$ & $66(29.7)$ \\
\hline Urban & $40(37.1)$ & $138(62.2)$ \\
\hline Slum & $24(22.2)$ & $18(8.1)$ \\
\hline
\end{tabular}

Table 2: Preeclampsia (incidence, onset, severity) in the study population.

\begin{tabular}{|c|c|c|c|c|c|}
\hline \multirow{3}{*}{ Study population ( $\mathbf{N}=\mathbf{3 3 0}$ ) } & \multicolumn{5}{|c|}{ Preeclampsia } \\
\hline & \multirow{2}{*}{$\begin{array}{l}\text { Total } \\
(n=19)\end{array}$} & \multicolumn{2}{|l|}{ Onset } & \multicolumn{2}{|l|}{ Severity } \\
\hline & & Early $(n=2)$ & Late $(n=17)$ & Mild (n=16) & Severe $(n=3)$ \\
\hline C.pneumoniae seronegative* $(\mathrm{n}=222)$ & $9(4.1)$ & $1(11.1 \%)$ & $8(88.9 \%)$ & $08(88.9)$ & $01(11.1)$ \\
\hline C.pneumoniae seropositive (untreated) $\dagger(\mathrm{n}=54)$ & $7(13.0)$ & $1(14.3 \%)$ & $6(85.7 \%)$ & $05(71.4)$ & $02(28.6)$ \\
\hline C.pneumoniae seropositive (treated) $†(\mathrm{n}=54)$ & $3(5.6)$ & 0 & $3(100 \%)$ & $03(100)$ & $00(00)$ \\
\hline
\end{tabular}

$*$ and $\dagger \mathrm{p}=0.023, \mathrm{OR}(\mathrm{CI})=3.208(0.227-45.19)$

Severe preeclampsia was seen in $28.6 \%(2 / 7)$ among seropositive untreated group, which was significantly higher compared to $11.1 \%(1 / 8)$ in seronegative group $(\mathrm{p}=0.023)$. The effect of treatment on severity of preeclampsia could not be evaluated because of the small number of severe pre-eclampsia cases and no case of severe pre-eclampsia in the treated group. Early onset (before 34 weeks) preeclampsia was seen in one case each in the C.pneumoniae seronegative and seropositive untreated groups, the difference in the two groups not being statistically significant. Seropositive treated group had no case of early onset preeclampsia. Hence the statistical significance could not be calculated.

There were a total of 44 preterm births (Table 3 ), the incidence being lowest in the seropositive treated group $(9.3 \%)$, compared to seronegative women $(12.6 \%)$ as well as seropositive untreated women $(20.4 \%)$; however, 
the difference was not statistically significant $(\mathrm{p}=0.189)$. The fetal outcome in terms of low birth weight was significantly improved with treatment. Mean birth weight $(\mathrm{kg})$ was $2.51 \pm 3.53,2.84 \pm 2.47$ and $2.84 \pm 3.55$ in seropositive untreated, seropositive treated and seronegative groups respectively. 48 neonates had birth weight $<2500 \mathrm{gm}$ (Table 3 ). The incidence of low birth weight (LBW) being highest in the in seropositive untreated group $29.6 \%(16 / 54)$ compared to $12.2 \%(27 / 222)$ in seronegative group $(\mathrm{p}<0.001$, $\mathrm{ARR}=0.204)$, and $9.3 \%(5 / 54)$ in the seropositive treated group ( $p<0.001$ ). The chance of having LBW baby in C. pneumonie seropositive untreated group was three times more as compared to seronegative group ( $\mathrm{OR}=3.04)$. There was an absolute risk reduction of $20.4 \%$ in the rate of LBW babies in seropositive treated group with the number needed to treat being 5 (range 3-18). However, there was no statistically significant difference in the neonates needing admission to NICU; those in the seropositive untreated group being 22.2\%(12/54) compared to $14 \%(31 / 222)$ in seronegative group, and $9.3 \%(5 / 54)$ in seropositive treated group.

Table 3: Neonatal outcome.

\begin{tabular}{|c|c|c|c|}
\hline & Preterm $(\mathrm{n}=44)$ & $\begin{array}{l}\text { Low birth weight } \\
(\mathrm{n}=48)\end{array}$ & $\begin{array}{l}\text { Admission to } \\
\text { nursery }(\mathrm{n}=48)\end{array}$ \\
\hline & $\%$ & $\mathbf{N}$ & $\%$ \\
\hline C.pneumonia seronegative $(\mathrm{n}=222) *$ & $12.6 \%$ & $27 \quad 12.6 \%$ & $14.0 \%$ \\
\hline C.pneumonia seropositive-untreated $(\mathrm{n}=54)^{\dagger}$ & $20.4 \%$ & $16 \quad 29.6 \%$ & $22.0 \%$ \\
\hline C.pneumonia seropositive-treated $(n=54)^{\beta}$ & $9.3 \%$ & $05 \quad 9.3 \%$ & $9.3 \%$ \\
\hline & $\begin{array}{l}* \text { and } \dagger \mathrm{p}=0.189 \\
* \text { and } \beta \mathrm{p}=0.642 \\
\dagger \text { and } \beta \mathrm{p}=0.174\end{array}$ & $\begin{array}{l}* \text { and } \dagger \mathrm{p}=.000 \text { OR }(\mathrm{CI}) \\
3.04(1.49-6.18) \\
* \text { and } \beta \mathrm{p}=0.993 \\
\dagger \text { and } \beta \mathrm{p}=0.000 \\
\mathrm{ARR}(\mathrm{CI})=0.204(0.054- \\
0.346) \mathrm{NNT}=5(18-3)\end{array}$ & $\begin{array}{l}* \text { and } \dagger \mathrm{p}=0.145 \\
* \text { and } \beta \mathrm{p}=0.499 \\
\text { † and } \beta \mathrm{p}=0.111\end{array}$ \\
\hline
\end{tabular}

\section{DISCUSSION}

In the present study the prevalence of C.pneumoniae $\operatorname{IgG}$ seropositivity among primigravidae estimated at 14-20 weeks of gestation was $32.4 \%(108 / 330)$, which was similar to other reports of Dadelszen V et al (39\%), Karinen et al (28.8\%), and El-Shourbagy (37\%); whereas higher seroprevalence was reported by Heine $(54 \%)$, Awoeleke (66\%) and Goulis et al $(77 \%) .{ }^{12-18}$ The present study as well as that of El-Shourbagy et al found no association of $C$. pneumoniae $\operatorname{IgG}$ seropositivity with age or BMI, even though two recent studies have shown that C.pneumoniae is capable of infecting preadipocytes and adipocytes and there could be a possible association between seroprevalence of C.pneumoniae and high BMI. ${ }^{18,25,26}$

In primary C.pneumoniae infection, $\operatorname{IgM}$ antibody response develops approximately 2-3 weeks after infection, and after 2-6 months it usually cannot be detected anymore. $\mathrm{IgG}$ and $\mathrm{IgA}$ responses develop more slowly and may reach high titres only 6-8 weeks after infection and may then remain elevated for long periods. Especially low titres may persist for several years. However, due to the shorter half-life of IgA antibodies, IgA positivity disappears faster than IgG positivity. IgG and $\operatorname{IgA}$ responses are faster in reinfections and can often be detected within 1-2 weeks after infection, whereas IgM response may not develop. Based on these facts we have done serology for serum $\operatorname{IgG}$ only as it is cost effective in detecting chronic or persistent infection of C.pneumonia.

For studying the association of seropositivity with preeclampsia we compared seropositive untreated and seronegative groups so that the data is not skewed due to effect of treatment; the incidence of PE being 13\% (7/54) and 4\% (9/222) respectively, indicating higher incidence of $\mathrm{PE}$ in seropositive untreated group compared to seronegative group $(\mathrm{p}=0.023)$. The first study to show an association between C.pneumoniae and PE was by Heine et al, who reported that $\mathrm{IgG}$ antibodies to C.pneumoniae at a titre of at least 1:16 were more common in women with PE than in women without (OR 3.1; $95 \%$ C.I. 1.2, 7.9) and women with the elevated titers of IgG to C.pneumoniae were found to have three-fold increased risk of PE. ${ }^{13}$ Similar result was reported by Aral et al, as well as our study that found the chance of getting PE to be 3.2 times higher in seropositive untreated group OR

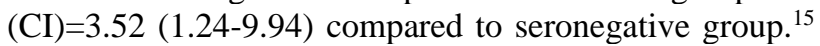
Gomez and Parry, observed that C.pneumoniae can infect human trophoblast cells and reduce trophoblast invasion into the uterine wall, a common feature in PE. ${ }^{19}$ In their case-control study to identify C.pneumoniae in trophoblast cells dissected by laser-capture microscopy from placentas in women with severe PE and controls delivered at term; C.pneumoniae DNA was identified significantly more frequently in trophoblast cells from cases $(15 / 48 ; 31 \%)$ than controls $(3 / 30,10 \%$; odds ratio 4.1 ; p.02). Karinen et al, also suggested that chronic 
C.pneumoniae infection and systemic low-grade inflammation may be associated with PE. ${ }^{16}$

Goulis et al, in UK population, did not find an association between $C$. pneumoniae infection and preeclampsia, however, significantly higher levels of IgA and IgM C.pneumoniae antibodies were found in parous women as compared to nulliparous $(\mathrm{p}<0.04)$, and in parous women with previous $\mathrm{PE}$ as compared to parous women with a normal obstetric history $(\mathrm{p} \leq 0.003)$; suggesting that there may be an association between C.pneumoniae and PE in this subgroup. ${ }^{14}$ El-Shourbagy et al, also supported the hypothesis that $C$. pneumoniae have a role in the development of PE. ${ }^{17}$ Awoleke et al, from Nigeria reported $77.6 \%$ seropositivity for the C.pneumoniae antibodies in PE compared to $58.1 \%$ in those without PE $(\mathrm{p}<0.05)$, and higher antibody titres in parous women with a previous history of PE compared with those without a previous history $(\mathrm{p}=0.0308)$, suggesting a link between C.pneumoniae IgG antibodies and PE. ${ }^{18}$

Some studies could not establish an association between $C$. pneumoniae and PE. Teran et al, reported that the odds ratio for PE among C. pneumoniae seropositive women was $1.8 \%$ compared to seronegative women; however, the difference was not statistically significant. ${ }^{20}$ Raynor et al and Chrisoulidou et al also found no difference in the rate of seropositivity between $\mathrm{PE}$ and normal pregnancy. ${ }^{21,22}$ Others, however, found that C.pneumonie may be a coprecipitating factor and its role in development of PE needs to be supported by further studies. Xie et al, examined C.pneumoniae $\mathrm{IgG}$ by ELISA and C.pneumoniae genomic DNA loads by real-time PCR in a case-control study on women with PE, normal term pregnancies and non-pregnant controls. $^{23}$ Although no association could be established between C.pneumoniae $\mathrm{IgG}$ sero-prevalence and $\mathrm{PE}$; C.pneumoniae genomic DNA, wherever measurable, were increased in women with PE compared with the normal pregnancy and their copy numbers were correlated with antiC. pneumoniae IgG concentrations $(\mathrm{p}<0.0001)$. Their data suggested an association between C.pneumoniae infection and PE; while not a uniform and singular precipitant of the maternal syndrome of PE, C.pneumoniae infection might be a co-precipitant and hence warranted further investigations. Mosbah and Nabiel, however, attributed no role to C.pneumoniae in the pathogenesis of PE unless supported by further studies. ${ }^{24}$

Regarding the association with the severity of preeclampsia, we found the proportion of severe PE to be $28.6 \%(2 / 7)$ among seropositive untreated women, as compared to $11.1 \%$ (1/9)) in seronegative group; the difference being statistically significant ( $p$ 0.023). The chance of getting severe preeclampsia was 3.2 times more in seropositive untreated group compared to seronegative group $(\mathrm{OR}=3.208,95 \% \mathrm{CI}$ 0.227-45.19). Gomez et al, in their case control study demonstrated that the presence of C.pneumoniae DNA in extravillous regions of placental samples from cases of severe PE was greater than in controls, but the difference was not statistically significant. However, none of the other published studies reported association with the severity of PE.

Dadelszen $\mathrm{V}$ et al, observed a significant difference in C.pneumoniae IgG prevalence in women with early onset PE (67\%), compared to those with late onset PE (38\%), normotensive IUGR (30\%) and matched normal pregnancy $(53 \%)$; early onset PE is associated with excessive innate immune response and inflammation and carries a far greater burden of maternal and fetal risks, probably because of reactivation of already present C.pneumoniae infection. ${ }^{12}$ Our study did not find significant difference in association of C.pneumonie infection between early and late onset PE. ElShuorbagy et al, also reported no association of seropositivity with the onset of PE. ${ }^{17}$

Following the treatment with azithromycin, El-Shuorbagy et al, showed statistically significant difference in the rate of PE among seropositive treatment and non-treatment groups as $6.5 \%$ and $19.1 \%$ respectively (p 0.014). ${ }^{17}$ In our study however, statistical significance was not reached, even though treatment with azithromycin did lower the incidence of PE in treated group; probably due to less number of cases of PE. El-Shuorbagy et al also found no significant reduction in terms of severity of PE, nor any difference in the birth weight $(3.3 \pm 0.4 \mathrm{~kg})$ in untreated and treated groups. ${ }^{17}$ This may also be explained by the fact that PE is a multifactorial disease and C.pneumonia could be one precipitating factor for the development of PE. Also, the recommendations for antibiotic therapy are not very clear, regimen used might not be sufficient in every patient. No other study has evaluated the role of antichlamydial treatment on the incidence of PE.

The strength of the study were that it was a prospective randomized controlled study, having a uniform population, confounding factors had been excluded and dropout rate was very less; limitation being a small study so statistical significance could not be achieved for the role of antichlamydial treatment in prevention of PE.

\section{CONCLUSION}

The prevalence of C.pneumonia IgG seropositivty was found to be $32.4 \%$ among primigravidae at $14-20$ weeks of gestation. These women were at higher risk of developing severe preeclmapsia as compared to the C.pneumoniae seronegative cases. Treatment with oral azithromycin resulted in reduction in the occurrence of pre-eclampsia amongst the $C$. pneumoniae seropositive cases; as well as significant reduction in the incidence of low birth weight babies in the C.pneumonie seropositive group. Further larger studies are recommended to establish the role of antichlamydial treatment on prevention of preeclampsia.

\section{Funding: No funding sources}

Conflict of interest: None declared

Ethical approval: The study was approved by the Institutional Ethics Committee 


\section{REFERENCES}

1. Lerberghe WV, Manuel A, Matthews Z. Make every mother and child count. Geneva, Switzerland: World Health Organization; 2005:230.

2. Dekker GA, Sibai BM. Etiology and pathogenesis of preeclampsia: current concepts. Am J Obstet Gynecol. 1998;179(5):1359-75.

3. Roberts JM, Taylor RN, Musci TJ, Rodgers GM, Hubel CA, Mclaughlin MK. Pre-eclampsia: an endothelial cell disorder. Am J Obstet Gynecol. 1989;161(5):1200-4.

4. Sacks GP, Studena K, Sargent IL, Redman CW. Normal pregnancy and pre-eclampsia both produce inflammatory changes in peripheral blood leukocytes akin to those of sepsis. Am J Obstet Gynecol. 1998;179(1):80-6.

5. Rustveld LO, Kelsey SF, Sharma R. Association between maternal infections and preeclampsia: a systematic review of epidemiologic studies. Matern Child Health J. 2008; 12(2):223-42.

6. Conde-Agudelo A, Villar J, Lindheimer M. Maternal infection and risk of preeclampsia: systematic review and metaanalysis. Am J Obstet Gynecol. 2008;198(1):7-22.

7. Kalayoglu MV, Libby P, Byrne GI. Chlamydia pneumoniae as an emerging risk factor in cardiovascular disease. JAMA. 2002;288(21):2724-31.

8. Gouda EA, Elharoun AS, Abdella MA. Involvement of Chlamydia Pneumoniae in atherosclerosis: Importance of methodology in determination the relation between them. Menoufiya Med J. 2008;21(1):55-66.

9. Sessa R, Nicoletti M, Di Pietro M, Schiavoni G, Santino $\mathrm{I}$, Zagaglia $\mathrm{C}$, et al. Chlamydia pneumoniae and atherosclerosis: current state and future prospectives. Int J Immunopathol Pharmacol. 2009;22(1):9-14.

10. Sattar N, Bedomir A, Berry C, Shepherd J, Greer I, Packard CJ. Lipoprotein subfraction concentrations in preeclampsia. Pathogenic parallels to atherosclerosis. Obstet Gynecol. 1997;89(3):403-8.

11. De Wolf F, Robertson WB, Brosens I. The ultrastructure of acute atherosis in hypertensive pregnancy. Am J Obstet Gynecol. 1975;123(2):164-74.

12. Dadelszen PV, Magee LA, Krajden M, Alasaly K, Popovska V, Devarakond RM, et al. Levels of antibodies against cytomegalovirus and Chlamydophila pneumoniae are increased in early onset pre-eclampsia. BJOG. 2003;110(8):725-30.

13. Heine RP, Ness RB, Roberts JM. Seroprevalence of antibodies to Chlamydia pneumonia in women with preeclampsia. Obstet Gynecol. 2003;101(2):221-6.

14. Goulis DG, Chappell L, Gibbs RG, Williams D, Dave JR, Taylor P, et al. Association of raised titres of antibodies to Chlamydia pneumoniae with a history of pre-eclampsia. BJOG. 2005;112(3):299-305.
15. Aral M, Guven MA, Kocturk SA. Chlamydia pneumoniae seropositivity in women with preeclampsia. Int J Gynaecol Obstet. 2006;92(1):77-8.

16. Karinen L, Leinonen M, Bloigu A, Paldanius M, Koskela P, Saikku P, et al. Maternal serum Chlamydia pneumoniae antibodies and CRP levels in women with preeclampsia and gestational hypertension. Hypertens Preg. 2008;27(2):143-58.

17. El-Shourbagy MA, El-Refaie TA, Sayed KK, Wahba KA, El-Din AS, Fathy MM. Impact of seroconversion and antichlamydial treatment on the rate of preeclampsia among Egyptian primigravidae. Int J Gynecol Obstet. 2011;113(2):137-40.

18. Awoleke JO, Ajayi GO, Adegbola O. Prevalence of Chlamydophila pneumonie antibodies in women with pre-Eclampsia in Lagos, Nigeria. West Afr J Med. 2012;31(4):253-8.

19. Gomez LM, Parry S. Trophoblast infection with Chlamydia pneumoniae and adverse pregnancy outcomes associated with placental dysfunction. Am J Obstet Gynecol. 2009;200(5):526.

20. Teran E, Escudero C, Calle A. Seroprevalence of antibodies to Chlamydia pneumoniae in women with preeclampsia. Obstet Gynecol. 2003;102(1):198-9.

21. Raynor DB, Bonney EA, Jang KT, Coto W, Garcia MS. Preeclampsia and Chlamydia pneumoniae: Is there a link? Hypertens Preg. 2004;23(2):129-34.

22. Chrisoulidou A, Goulis DG, lliadou PK, Dave JR, Bili $\mathrm{H}$, Simms C, et al. Acute and chronic Chlamydia pneumoniae infection in pregnancy complicated with preeclampsia. Hypertens Preg. 2011;30(2):164-8.

23. Xie F, Hu Y, Magee LA, Money DM, Patrick DM, Brunham RM, et al. Chlamydia pneumoniae infection in preeclampsia. Hypertens Preg. 2010;29(4):468-77.

24. Mosbah, Nabiel Y. Helicobacter pylori, Chlamydiae pneumoniae and trachomatis as probable etiological agents of preeclampsia. J Matern Fetal Neonatal Med. 2016;29(10):1607-12.

25. Bouwman JJ, Visseren FL, Bouter KP, Diepersloot RJ. Infection-induced inflammatory response of adipocytes in vitro. Int J Obes. 2008;32(6):892-901.

26. Shi Y, Liu Y, Murdin A, Raudonikiene-Mancevski A, Ayach BB, Yu Z, et al. Chlamydophila pneumoniae inhibits differentiation of progenitor adipose cells and impairs insulin signaling. J Infect Dis. 2008;197(3):439-48.

Cite this article as: Sindhu L, Yadav B, Batra A. Prevalence of Chlamydia pneumoniae seropositivity in early pregnancy and its association with preeclampsia among primigravidae in Indian population. Int J Reprod Contracept Obstet Gynecol 2019;8:3964-9. 